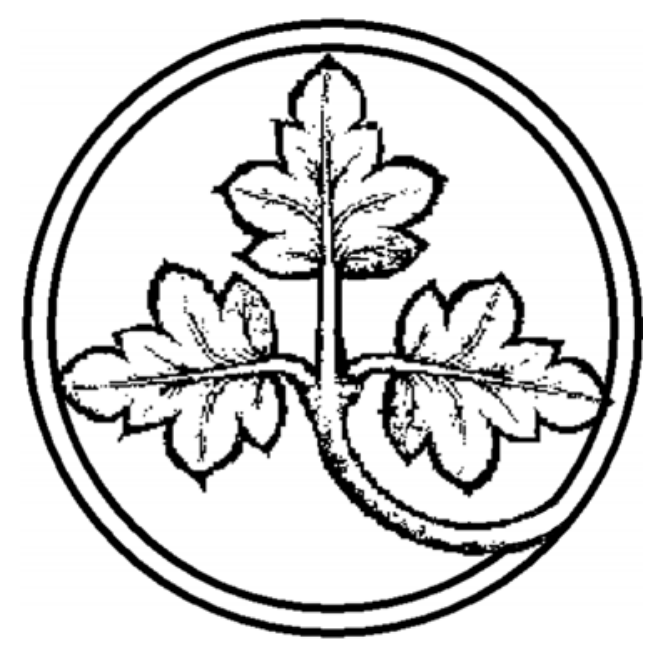

\author{
Preprints of the \\ Max Planck Institute \\ for Research on Collective Goods \\ Bonn \\ 2004/4
}

Social Dilemmas,

Revisited from a Heuristics Perspective

Christoph Engel 


\section{Social Dilemmas, Revisited from a Heuristics Perspective}

Christoph Engel

April 2004 


\section{Social Dilemmas, Revisited from a Heuristics Perspective}

\section{Table of Contents}

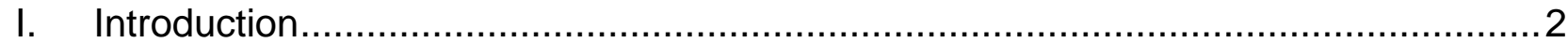

1. Social Dilemmas in a Rational Choice World ..............................................

2. The Different World of Heuristics .............................................................. 3

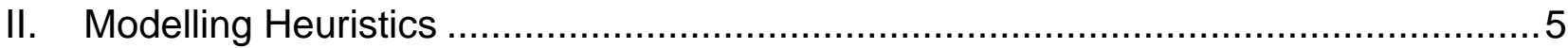

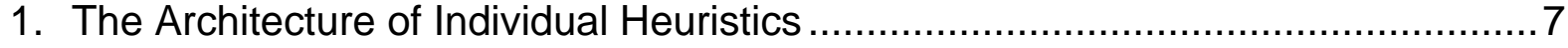

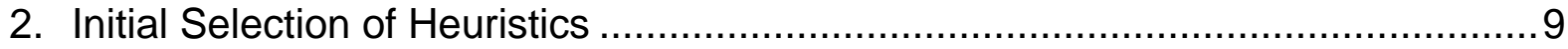

3. More Complex Decision-Making ........................................................... 10

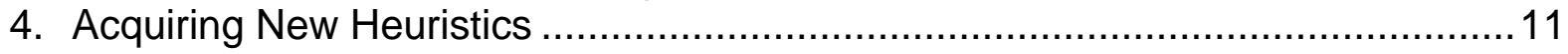

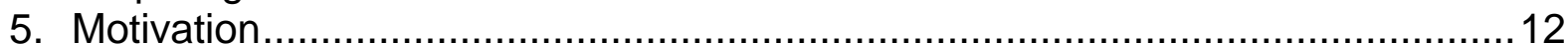

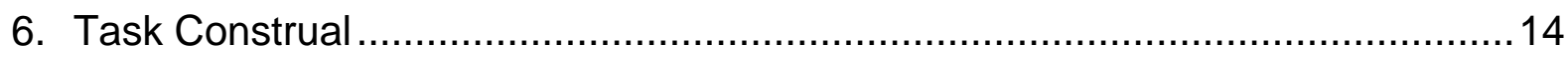

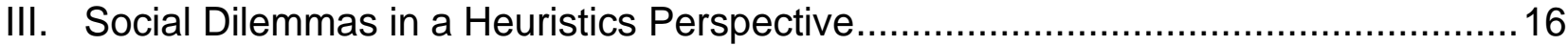

1. Predicting the Absence of a Social Dilemma ............................................ 16

2. Explaining Perceived Social Dilemmas ..................................................... 18

a. Socially Detrimental Heuristics ....................................................... 18

b. Architecture of Heuristics ................................................................ 19

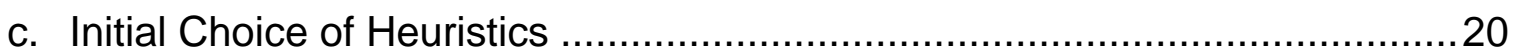

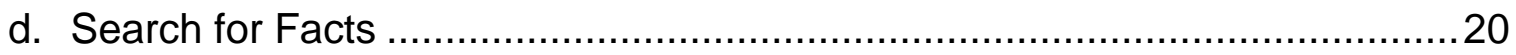

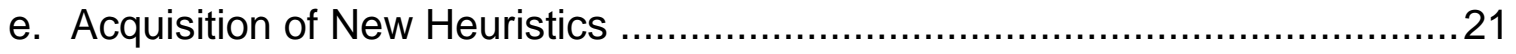

f. Switch to Rational Reasoning ............................................................. 21

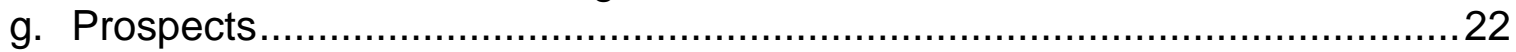

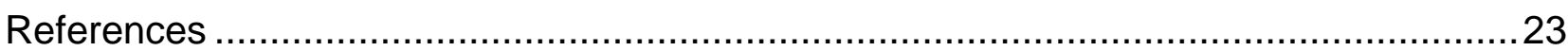

Helpful comments by Gerd Gigerenzer and Werner Güth are gratefully acknowledged. Thanks also go to the participants of the Ringberg Workshop on Behavioural Analysis in the Area of Common Goods, and to the Institutional Design Unit of the Bonn Institute for comments during presentations of an earlier version of this paper. 


\section{Introduction}

When God expelled Adam and Eve from paradise, he created rationality. Not only would humans have to cope with scarcity, and hence have to trade some desired goods for others. They would even be pitted against each other. Individually rational behaviour would lead to social dilemmas.

This is how economists describe the human condition. Not wrongly, of course. But psychological work on heuristics demonstrates that God was more inventive than economists allow for. He endowed humans with an entire toolbox for decision-making. Most of these tools are heuristics. They are ready-made and context-specific. Does this cast a more benign light on human destiny? Or does it make their fate even more miserable? It depends. Does this allow us to better understand perceived social dilemmas, and to better advise institutional designers? Yes. This paper thus serves a prognostic and an explanatory purpose. It does so by modelling, where the rational choice model serves as a contrast.

\section{Social Dilemmas in a Rational Choice World}

Climate change presents a standard example. Scientists say it is generated by an increase in $\mathrm{CO}_{2}$ emissions. The relevant factor is total emissions worldwide on a long-term scale. Only part of the problem is man-made. Most of the natural sources of $\mathrm{CO}_{2}$, like volcanoes, are beyond human control (NATIONAL RESEARCH COUNCIL 2001).They are irrelevant for policy-making, and hence for the definition of the social problem. Specifically, if policy-makers concentrate on these sources, policy options are narrowed down to adaptation from the start. Mitigation is no longer considered.

From a mitigation perspective, economists use public goods theory for modelling climate change (CORNES and SANDLER 1996). The analysis comes in three steps. (1) Individual and social rationality are seen to be in opposition. The utility of generating $\mathrm{CO}_{2}$ by energy consumption is private, the negative effects on climate are social. Therefore individuals do not have an incentive to save energy, or to switch to more costly primary sources of energy. (2) The individual willingness to solve the problem is hindered. Benevolent actors anticipate that others will free-ride on their efforts. (3) Agreement ex ante is futile. Sovereign intervention notwithstanding, nobody has an incentive to keep his word (OSTROM 1998).

Consequently, rational choice analysts call for changing incentives such that individual and social rationality become realigned. Political practice has zoomed in on one tool: tradable permits. For practical reasons, currently only industries are targeted that are high in energy consumption, like the producers of concrete. Such industries can, however, credibly threaten to relocate to foreign countries. Consequently, in practice, thresholds are so high that the environmental effect of the permit scheme remains close to zero. As long as large countries like the US ignore the policy problem, it would therefore be attractive for policy-makers to target consumers. They are captive targets. Their consumption of fossil fuels in heating, air-conditioning, and automobile driving is 
far from negligible. If one wants to understand how a reduction of $\mathrm{CO}_{2}$ emissions from these sources could be brought about, one must understand what drives this behaviour in the first place.

The rational choice analysis of social dilemmas starts from a number of explicit and implicit assumptions about behaviour and context. Actors are modelled as homines oeconomici (BECKER 1976). They have a well-defined utility function. Before taking action, they thoroughly analyse the situation, taking all available information into account. They calculate the expected value of inactivity and compare it to the expected value of any potential action. They choose the course of action that maximises utility. Whenever there is a change in the environment, i.e. in the opportunity structure, they reoptimise. They do so instantaneously. Actors solve all decision-making problems the same way. The mental tool thus has zero domain specificity. Actors never make mistakes. They are unboundedly sophisticated. They do not face cognitive limitations (for a critical view, see GigerEnzER, TODD et al. 1999). All this is known to all other actors. Actors anticipate the behaviour of their counterparts, and specifically their counterparts' reactions to their own action.

Rational choice analysis assumes away context (GRANOVETTER 1985). Specifically, all context is modelled as part of the opportunity structure. Social problems are analysed in an institution-free state of nature (HoDGSON 1988). Implicitly, the world is assumed to be fairly certain and to be cognitively accessible (THOMPSON, ELLIS et al. 1990). Consequently, task construal is a mechanical exercise. It consists of exploiting the available information.

\section{The Different World of Heuristics}

Some of these assumptions are patently unrealistic. Much of the rhetoric in behavioural economics and in psychological decision theory therefore reads like a realism crusade. Yet, such a crusade is epistemologically naive. Noone who engages in explanation or even prognosis can avoid modelling. Assuming some elements of reality away is the price one has to pay for gaining insight into the mechanisms that hold the world together. The following is thus deliberately an exercise in modelling. But instead of just modelling rational, or, better, deliberate reasoning, it models actors who use simple heuristics for decision-making most of the time.

Like the rational choice model, the following model assumes a lot of things away. It allows for two types of decision-making tools only: deliberate reasoning and decision heuristics. It ignores any other decision modes (GOLDSTEIn and WEBER 1997; PAYNE, BETTMAN et al. 1997). For simplicity, deliberate reasoning is modelled the same way as in rational choice analysis. Actually, even when people reason consciously, they do not follow the norms of rational choice theory. They either engage in narrative reasoning (PENNINGTON and HASTIE 1997; DAWES 1999) or in reason-based choice (Pennington and Hastie 1993; Goldstein and WeBer 1997; Shafir, SiMONSON et al. 2000). 
Moreover, individuals use heuristics for much more than just decision-making. Heuristics guide attention (HogARTH, GiBBS et al. 1997: 259 f.), perception (LeVINSON 1995), and judgement (NISBETT and Ross 1980: 17-42). Heuristics thus contribute to a process of otherwise conscious reasoning. This is ignored here since the paper is interested in making the contrast between rational reasoning and decision-making by heuristics as stark as possible. This also explains why the conscious and deliberate use of heuristics is not considered here (for an example, see GIGERENZER, ToDD et al. 1999: 3-5).

This is one difference between my research agenda and that of the GIGERENZER group. The researchers of the latter group pursue two overlapping, but non-identical goals. They want to demonstrate why simple decision rules can perform conspicuously well. This ultimately is an exercise in mapping decision rules to features of the problem space ${ }^{1}$. Put differently, this line of research has a normative goal. It defines the conditions under which rational reasoning yields poor results. This paper does not share this interest. Secondly, the GIGERENZER group aims to show how individuals actually deal with decision-making problems. This paper is only interested in this second, descriptive question. The richer model of decision modes is meant to draw a more appropriate picture of social dilemmas, where appropriateness is assessed from the perspective of potential institutional interventions aiming at social betterment. People often use simple heuristics. In the area where both goals of the GIGERENZER group overlap, they do so in response to features of the problem space. But empirically, the use of heuristics is not confined to such problems. People often also rely on them if the characteristics of the problem space allow for variants of rational reasoning.

This paper looks exclusively at decision-making by isolated individuals. This excludes collective and corporate actors (COLEMAN 1990: chapters 9, 13, 16), and individuals who consult others before taking action.

This paper follows rational choice analysis for problem description. It revisits social dilemmas, as defined in rational choice terms, but it has different assumptions about behaviour. It also takes welfare maximisation as the norm. None of this is natural from a heuristics perspective. It is done in the interest of making the differences between both approaches as visible as possible.

By way of division of labour, this paper is confined to problem definition. A natural complement would consist of drawing out the implications for institutional design. This is, however, done by a different working party. Consequently, the institutional designer is assumed to be a standard rational actor. For him, the richer behavioural model only affects the analysis of the social problem, not his own activity.

Criticising rational choice theory for its behavioural assumptions is nothing new. Analysts from that school typically respond by pointing to the predictive power of their model. Conceptually, this implies that humans behave "as if" they were rational. Individualism is said to be methodological, not ontological (FRIEDMAN 1953; BLAUG 1980). This claim is intellectually akin to behaviourism 
in psychology. Regardless of the mental mechanisms employed in action, people are expected to respond in a foreseeable manner to the presence of reinforcers in the environment (SKINNER 1938). The cognitive revolution in psychology has demonstrated why this is often not true (CHOMsKy 1959). The choice between modelling behaviour and modelling behavioural dispositions matters.

This paper is not exclusively cognitive. It aims to demonstrate that introducing heuristics into the behavioural assumptions matters for understanding and predicting social dilemmas. This is not to say that heuristics cannot offer mental shortcuts for behaviour in line with rational choice norms. But this does not hold for all heuristics. Modelling heuristics even makes a difference if the social dilemma, like the climate change problem, only results from aggregate behaviour, and not from individual behaviour. As will be shown, many politically relevant effects of heuristics are not erradicated in the aggregate either. 


\section{Modelling Heuristics}

For the sake of simplicity, the model used here allows for no more than two decision modes: rational reasoning and heuristics. Heuristics are the default mode. Rational reasoning is only employed in exceptional cases. This model also explains these exceptions. Rational reasoning is modelled in accord with the standard in economics. The heuristics model has very few mandatory components; instead, it has further optional components, as outlined in figure 1:

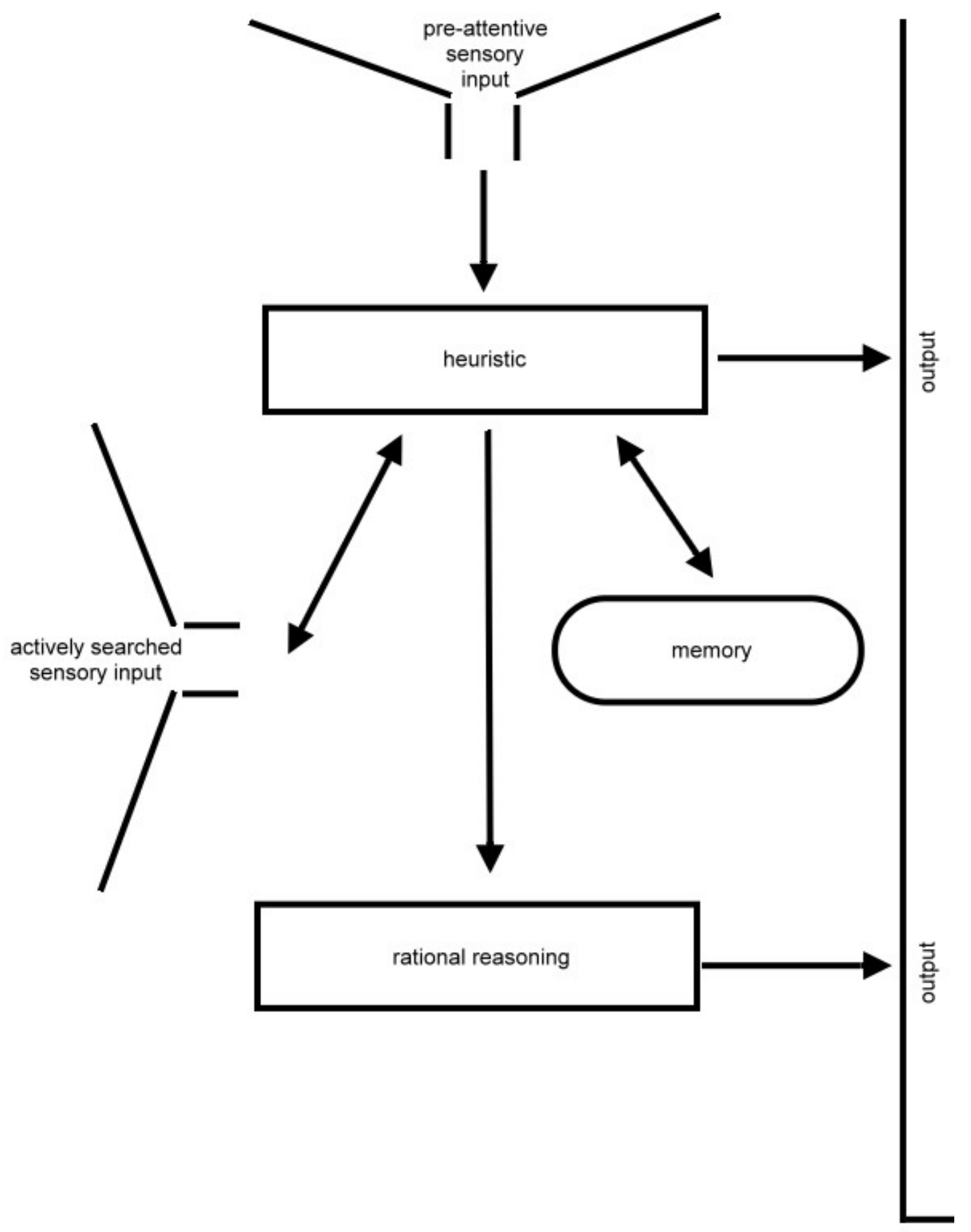


Not all of these steps need be taken to initiate behaviour. In the most simple case, the individual receives some sensory input. This input seemingly fits to the domain of a heuristic stored in the memory. This initial hypothesis is corroborated by matching. The cue is present. The heuristic fires. This then makes for the core model, as sketched in figure 2:

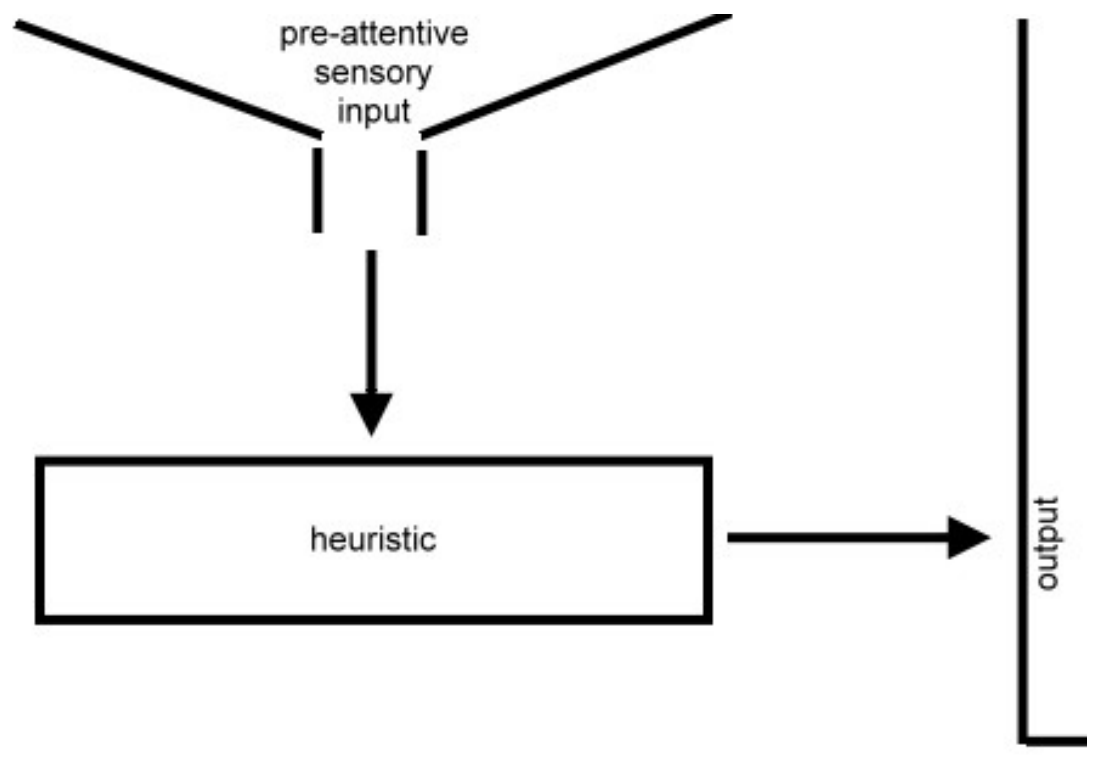

But decision-making by heuristics can be more complex. If the initial hypothesis is refuted, other heuristics may be retrieved from memory. If the original sensory input is inconclusive, the individual may search for more facts. If matching with any of the heuristics originally retrieved fails, the individual may solve the problem by adopting or generating a new heuristic. If using heuristics to make decisions does not work out, or does not seem appropriate, the individual may switch to rational reasoning. Moreover, the individual perpetually improves the stock of heuristics by way of a feedback mechanism. A richer model can allow for a separate mechanism for task construal.

\section{The Architecture of Individual Heuristics}

Heuristics have two characteristic properties. They are radically simple tools for decision-making. Although their decision algorithm ignores most information about the environment, they perform conspicuously well. This is due to their second property. Heuristics are ecological. They are not all-purpose tools, but they are context specific (GIGERENZER, TODD et al. 1999). These two properties are modelled as follows: 


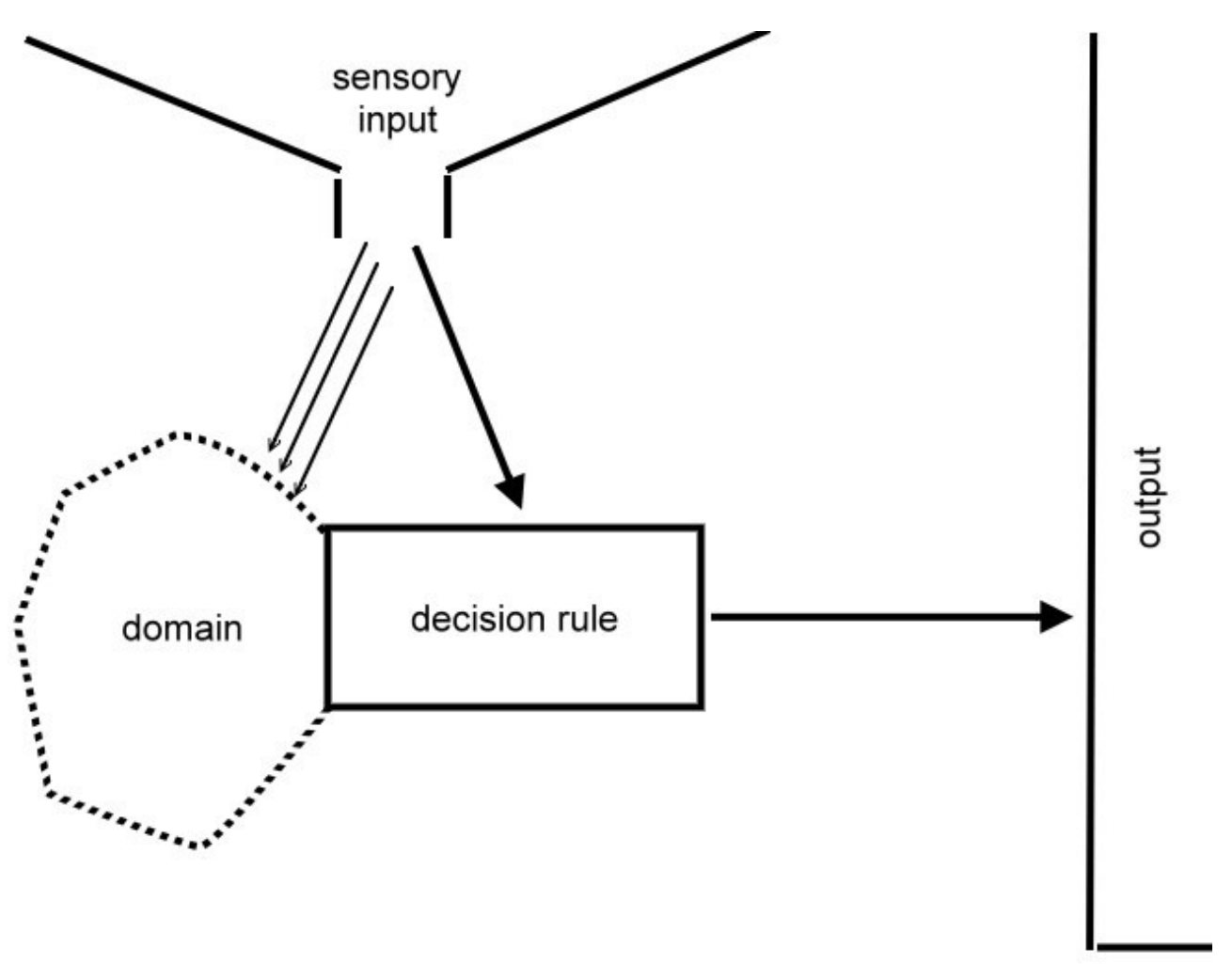

Heuristics have a dual architecture. The actual tool for decision-making is labelled the decision rule. For simplicity, it is assumed that the rule combines exactly one input with the output. If this one cue is present, the heuristic fires. But the model is open to more complex decision rules, like the one presented in GigerEnZER, TODD et al. (1999: 3-5). The only restriction concerns the relationship between the cue material and the output. This relationship must be fully specified ex ante.

This is different for the second element of a heuristic. It is labelled the domain. This second element is assumed to be associational. It is the ecological component. Here, the criterion is not the presence or the absence of a cue, but the perceived goodness of fit. The decision rule is thus precisely defined, while the domain is only described. The decision rule is strict, while the domain is open to matching. Information about the cue defines when the heuristic is to fire, while information about the domain is used in an associational way.

The decision rule is purely mechanical. It has no judgmental component. There is no weighing of pros and cons. The mechanism is digital. If the cue is present, the heuristic fires. If the cue is absent, the heuristic remains inactive. There is no decision being taken. There is no motivational component.

There are several options available for modelling the domain. In the most simple design, the domain would consist of a rather large number of equally weighted criteria. The brain would check for the presence of these features in the environment. Goodness of fit would be defined by an aspiration level - much as satisficing is in the motivational camp (SIMON 1955; SIMON 1979). In this model, a conceptual tool traditionally used for understanding the decision rule would thus be transposed to the matching process. If, say, $80 \%$ of these features were perceived, the heuristic would be deemed applicable (cf. GoLDSTEIN and HOGARTH 1997: 7; ANDERSON, BothelL et al. 
2003: ***19). Physiologically speaking, this is conceivable. The brain is an extraordinarily powerful tool for information processing, with some $10^{11}$ nerve cells, and some $10^{14}$ synaptic links (SINGER 2003: 745). Much of the performance of the brain can be traced back to the fact that it consists of a well-organised, vast knowledge base (ANDERSON 2000: 346; GLIMCHER 2003: 255267).

There is, however, compelling evidence of a more intelligent mechanism. Sensory input usually is not processed piece by piece. Down to the physiological level, the brain is permanently striving for more and more aggregate assemblies (HEBB 1949: $60 \mathrm{f}$. and passim). It works by associative clusters that are activated jointly (STRACK and DEUTSCH 2002: ***7 and 11). At the symbolic level they condense in natural categories (RAKISON and OAKES 2003). These can take one of two forms: a schema or an exemplar (ANDERSON 2000: 348). Exemplars remain fully contextualised (ANDERSON 2000: 350-352), while schemata abstract from some aspects of the context (HEAD 1920: 605-607; BARTLETT 1932: 199-204; GOLDSTEIN and WEBER 1997: 586, 598; ANDERSON 2000: 348-350). They single out more and less characteristic features, and give the former greater weight in matching. Put differently, whenever possible, the brain does not solve problems of categorisation merely by deploying brute computational force. It economizes resources by attempting to make sense out of its environment (cf. TURNER 2001). Although the mechanism is thus typically more complicated, it retains the idea of partial matching. To apply a heuristic, the perceived features of the environment need not fully coincide with the situation that has helped the individual forge the exemplar. Likewise, not all the features of a schema, not even all highly characteristic ones, must be present in the environment for the heuristic to be applied. The perceived goodness of fit must be satisfactory, not maximal.

The task of categorising by way of schemata remotely resembles the task of doctrinal lawyers. The similarity is most pronounced in reference to common law. Its prime source is precedent. It is more abstract than an exemplar. Later judges do not just look for similarities across cases, as in Islamic law. Yet it is not as abstract as continental law either, which strives for as much decontextualisation as possible. In common law, later judges distil the ratio iuris from precedent. But whenever there is doubt about the actual confines of the rule, they go back to the original case. The parallel to the law is helpful since it demonstrates a further possibility for the architecture of the heuristic. Legal rules, at least in their simple form, have an if-then structure. If the features of a case match those spelt out in the rule, the rule applies. In principle, practising lawyers might turn this into a two step exercise: first can they try to match the case to the rule; then they can apply it. But actually, when lawyers are engaged in matching, they always keep the potential outcome in mind (ENGISCH 1983). The same possibility exists for heuristics. Matching need not be confined to the domain. It might include the cue right from the beginning. This can serve to preclude potentially useless matching. If the cue is not present, the heuristic is discarded without further ado. This can, however, only be stated here as a possibility. There does not yet seem to be empirical evidence. 


\section{Initial Selection of Heuristics}

The contextual character of heuristics implies that individuals have a whole array of heuristics at their disposal. Since the domain is matched associationally, there is at least a possibility that one and the same situation will fall into the domain of several heuristics. There are two reasons that this matters for the behavioural output. One and the same cue may feature in more than one theoretically applicable heuristic (MANTZAVINOS 2001: 24). In that case, there is competition between several heuristics (ANDERSON, BOTHELL et al. 2003: ***19). Moreover, the individual may only test heuristics that are applicable, but that do not have an observable cue in their decision rule. If such heuristics are tested, the individual may engage in more complex forms of decision-making, although he would have an applicable heuristic with a pertinent cue at his disposal.

The key to understanding how heuristics are selected lies in understanding how they are stored. When it comes to decision-making, they must be retrieved from memory. Consequently, the model for resolving competition among decision-making tools must rely on what is known about how items are retrieved from memory. There are four components: the recency and frequency of usage; an associative component; the degree to which the heuristic matches current retrieval specifications; and a noise component, introducing an element of stochasticity (ANDERSON and LEBIERE 2003: ***4.2).

The first component is purely statistical. A heuristic is more likely to be retrieved, the more often it has been used in the past. But this general base rate of activation is corrected with respect to recency. The latter effect underlies priming. If a cue has been activated recently, it becomes more likely that a heuristic will be retrieved that has that cue in its domain (LASHLEY 1951).

The associative component is basically the same one that has been described when discussing how matching works (BARTLETT 1932: 208; ANDERSON 2000: 206). It relies on mental representation by way of schemata and exemplars (BARTLETT 1932: 212; ANDERSON 2000: 210 f.). The more sense a heuristic seems to make in the context at hand, the more likely retrieval is. Memory thus exploits meaning (BARTLETT 1932: 204 f.; ANDERSON 2000: 213-221).

The retrieval and use of heuristics are assumed here to be subconscious. This does not, however, rule out central control. In principle, there are three mechanisms involved in retrieval: attention, attitudes, and instinct. They wield their effects over different time-spans. Attention generates short-term selectivity in central action. Attitudes have a mid-term effect. Instinct is innate, and hence it has a long-term effect (HEBB 1949: 141).

\section{More Complex Decision-Making}

Thus far, only the most simple mechanism has been considered. There is some sensory input. It triggers the retrieval of one heuristic from memory. The brain tries to match the observed features of the environment to the domain of the heuristic. If the aspiration level is met, the brain checks to see whether the cue is present. If it is, the heuristic fires. 
What does the brain do if this first attempt fails? The easiest reaction is to repeat the same steps until a pertinent heuristic is found. But the brain has three more options. It may actively search for more facts. If it does this, it goes beyond pre-attentive sensory input (cf. LEWIS 2004: ***12 of pdf). It may acquire or generate a new heuristic. And it may switch to rational reasoning, i.e. it may change the decision mode. All of these options are costly. Correctly anticipating the cost of each of these four options leads to the rationalistic nightmare of subjective expected utility theory (SAVAGE 1954). Engaging in this would be anti-parsimonious to the extreme. In order to avoid doing this, the mechanisms underlying retrieval from memory must be extended to these metadecisions.

The first solution of the meta-choice problem is a simple probabilistic mechanism. It can be analysed in parallel to the decision rule of heuristics. There, the mechanism has been dubbed a stopping rule (SIMON 1972; GigerEnZER, TODD et al. 1999: 10 and passim). Theoretically, this mechanism could be extended to guide the meta-choice among the three options for introducing greater complexity into decision-making by heuristics. If this were to be done, the brain would set a limit to each type of additional decision-making effort, and specify ex ante the order in which it would use each of them. It might, for instance, determine to try out 10 alternative heuristics. If this failed to bring positive results, it might engage in a search for facts for five minutes. If this search did not work out either, it might try to generate one new heuristic. If this were not successful, it might switch to conscious reasoning.

This is conceivable, but it would be very rigorous, and potentially also unduly costly. For such an ex ante specification could not possibly be appropriate across the board. Some contexts are information rich, and it is relatively easy to uncover more information in them. Here, active searches are promising. In other contexts, the perceived degree of uncertainty is high. Here, observing how others with greater experience handle decisions is potentially more promising. Within the model, this would mean acquiring a new heuristic. In yet other contexts, sophisticated tools for rational reasoning are easily available, and they have a good record. Here, quickly switching to rational reasoning seems the best policy if initial attempts at deciding with heuristics do not work out.

These meta-decisions may use the same four mechanisms that memory offers for retrieval. The general base rate of activation and the recent rate of activation offer a first approximation. The brain decides how to decide the same way as it usually has in this domain. In appropriate cases, this meta-rule may be overridden by associative impulses. One feature from the environment triggers a switch to a meta-decision that is unusual for the domain. The meta-decision may also be guided by central impulses, like a personal decision-making style. For instance, some people are more inclined to rational reasoning, others rely more on experience. Such personality traits can be introduced into the model as attitudes towards more complex decision-making, once the initial attempt at using a heuristic has failed. Finally, there is a noise component, i.e. a certain degree of unpredictability with respect to the meta-decisions. 


\section{Acquiring New Heuristics}

Alternative heuristics are retrieved from memory the same way as the initial heuristic. Both an active search for facts and a switch to rational reasoning are also straightforward activities. But how does the brain acquire new heuristics? This is still very much uncharted territory. The following component of the model must therefore remain fairly sketchy.

In principle, two options exist. The brain can take a new heuristic from the environment, or it can generate it by central activity. The former is learning. In principle, any learning mechanism might be used, ranging from classic conditioning to formal instruction (ANDERSON 2000). But one learning mechanism seems particularly likely: observational learning (BANDURA 1986). It allows for the cultural transmission of heuristics (GIGERENZER, TODD et al. 1999: 92). Individuals need not have experiences of their own. They may observe how others fare in a context unknown to them. From this, they generate a hypothesis about mechanism - a model, as learning theorists put it (BANDURA 1986: $48 \mathrm{f}$.).

There are two ways of centrally generating new heuristics: one incremental and one fundamental. Heuristics are particularly well-suited for incremental change. The domain is delineated by way of schemata or exemplars. Both lend themselves to the integration of new elements. Likewise, some elements may be dropped. In both cases, one heuristic may be extended to a new domain by analogy (cf. BARTLETT 1932: 206).

Central activity is, however, not confined to incremental change. Fundamental change has been dubbed insight (HEBB 1949: 132, 134, 159 f., 164), accommodation (PIAGET and GABAIN 1932), and blending. The latter concept offers a particularly plausible mechanism for the generation of new heuristics. Individuals unpack previously stored heuristics, and compose elements in new and unprecedented ways (TURNER 2001).

\section{Motivation}

In psychological terms, rational choice is a theory of motivation. The individual wants to maximise utility, given the current state of the environment. Heuristics, as modelled here, do not have a motivational component at all. The decision rule is strict: if the cue is present, the heuristic fires. Matching the perceived environment with the domain is an exercise in goodness of fit, not in the maximisation of any goal. Also the selection of heuristics, the active search for facts, and the acquisition of new heuristics are driven by matching, not by a goal. Only rational reasoning has an independent goal-component (modelled here as in rational choice analysis). Is this to say that decision-making by heuristics ignores utility?

The answer comes in two parts. The motivational part is not in the architecture of the individual heuristic, but in the mapping of heuristics to domains. And the individual is endowed with a feedback mechanism that sees to it that decision-making by heuristics is consistent with the individual's (or the species') goals. 
Despite their parsimony, heuristics perform well since they are adaptive (GIGERENZER, TODD et al. 1999: 21). At face value, this is exclusively a statement about mechanism. The individual is freed up from calculating the pros and cons of a decision in the concrete situation. He can rely on a ready-made decision-making tool for the purpose. The calculations have been done earlier. It is enough for the individual to check to see whether the new situation comes sufficiently close to the situation for which the decision-making tool has been generated in the first place. Consequently, in decision-making that uses heuristics, judgement and the actual decision-making are two things. The judgmental component is confined to the generation of new heuristics. It is removed from the actual decision-making.

This statement about mechanism has an important implication. There is no longer a need for the individual to make any judgment on his own. It suffices for the individual to pick ready-made decision-making tools from trusted sources. Specifically, the individual can choose between centrally generating new heuristics and learning by observation how others solve similar problems. From a social perspective, this has two advantages. Individuals can economize on judgmental effort. And they can exploit costly experiences that others have had. They do not even need to directly observe these experiences. It is enough if they adopt the foreign decision-making rules that have resulted from these experiences.

Constructivists like to show that entire populations can survive for a long time in more or less fictitious environments (BERGER and LUCKMANN 1967). Even rational choice theorists admit that there are situations where it is individually rational to ignore base data, and to anticipate how others wrongly see the world instead. This is how they explain herding, evident, for example, in a speculative bubble on the stock market (BRU and VIVES 2002). The greater the complexity and uncertainty, the more difficult it is to get at a reliable understanding of "the reality" (ENGEL, HALFMANN et al. 2002). This has two implications. In decision-making, small mistakes are hard to avoid. But individuals are also well-advised to aim at avoiding big mistakes. This can be done simultaneously and sequentially. The simultaneous mechanisms have already been outlined. If it becomes dubious that the heuristic actually matches the domain, the individual may try out different heuristics stored in memory. He may engage in an explicit search for additional facts. He may adopt or generate new heuristics, or he may switch to rational reasoning. But there is also a sequential option. It uses the effect of actual decisions on the environment as input for fine-tuning the domain of heuristics. This is done via feedback, as outlined in figure 4: 


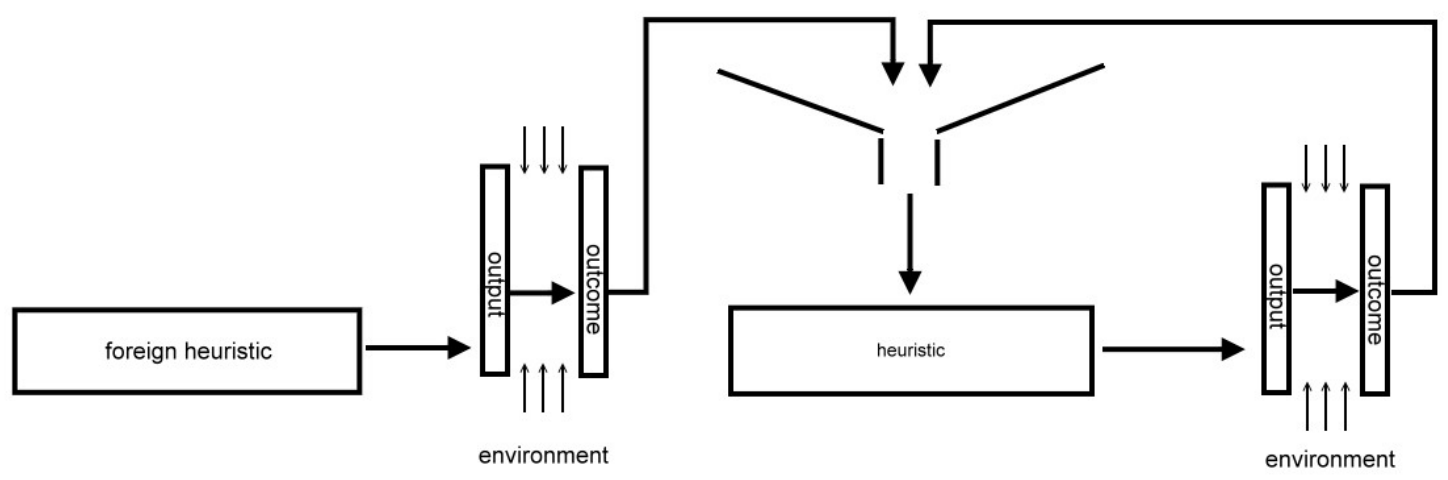

There is evidence of this kind of feedback even for the most basic functions of the brain (GLIMCHER 2003: 87-95). It therefore does not seem far-fetched to expect the same at the more aggregate level of heuristics. In principle, the individual has two options. He may use the performance of his own behaviour as feedback, or he may observe how his peers do in the same environment.

A distinction familiar in political science helps us to understand a further implication. Political scientists refer to political action, say, a new statute, as output. They distinguish the outcome from this, namely the effect of the new rules on the behaviour of addressees. Likewise, using a heuristic generates behaviour as an output. But for feedback, the relevant information is the outcome, i.e. the effect of behaviour in the environment. It results from the interaction between the output and other environmental factors.

Furthermore, feedback only makes sense if there is a benchmark. In principle, this could be utility, as used in rational choice analysis. But in the fundamentally uncertain world for which heuristics are made, this would be surprising. It is more likely that the benchmark itself is flexible, and that it is developed in interaction with the environment. Aspiration adaptation theory is a way of formalising the idea (SELTEN 1998). In principle, the observing individual might infer a changing benchmark from changes in observed behaviour. But the richer the set of potentially relevant criteria, the more it will help the observing individual if others do not just behave, but visibly endow their action with meaning.

\section{Task Construal}

There is one final surprise in the basic model: it has no separate component for defining the problem. Pre-attentive sensory input alone sets the mental machinery in motion. It is possible to enrich the model by adding a problem definition component. It is, however, important to understand that such a component is not a necessary ingredient. For the problem definition can be embedded in the domain of the heuristic, no less than the motivational part. Two examples illustrate the possibilities. 
In the first example, an individual perceives a snake in the environment. This information alone triggers the decision rule: freeze. In the second example, the subject is in a cheap bar (the domain). In one corner, guests start shouting (the cue). The heuristic fires: flee. Apparently this individual has learned that a row in a cheap bar can quickly turn violent. The difference between the two cases lies in the thickness of the domain. In the first case, it is extremely thin: no more than the cue is needed. In the second case, the domain is thicker, and hence separable from the cue.

Different examples are conceivable. The individual may not always want to flee when there is a risk of a violent row in a bar. He may want to come to the rescue of a friend. Or he may prefer watching a good match when enough alcohol makes him feel invincible. One may conceptualise such situations by adding a further component to the model. This would then make for the architecture shown in figure 5 :

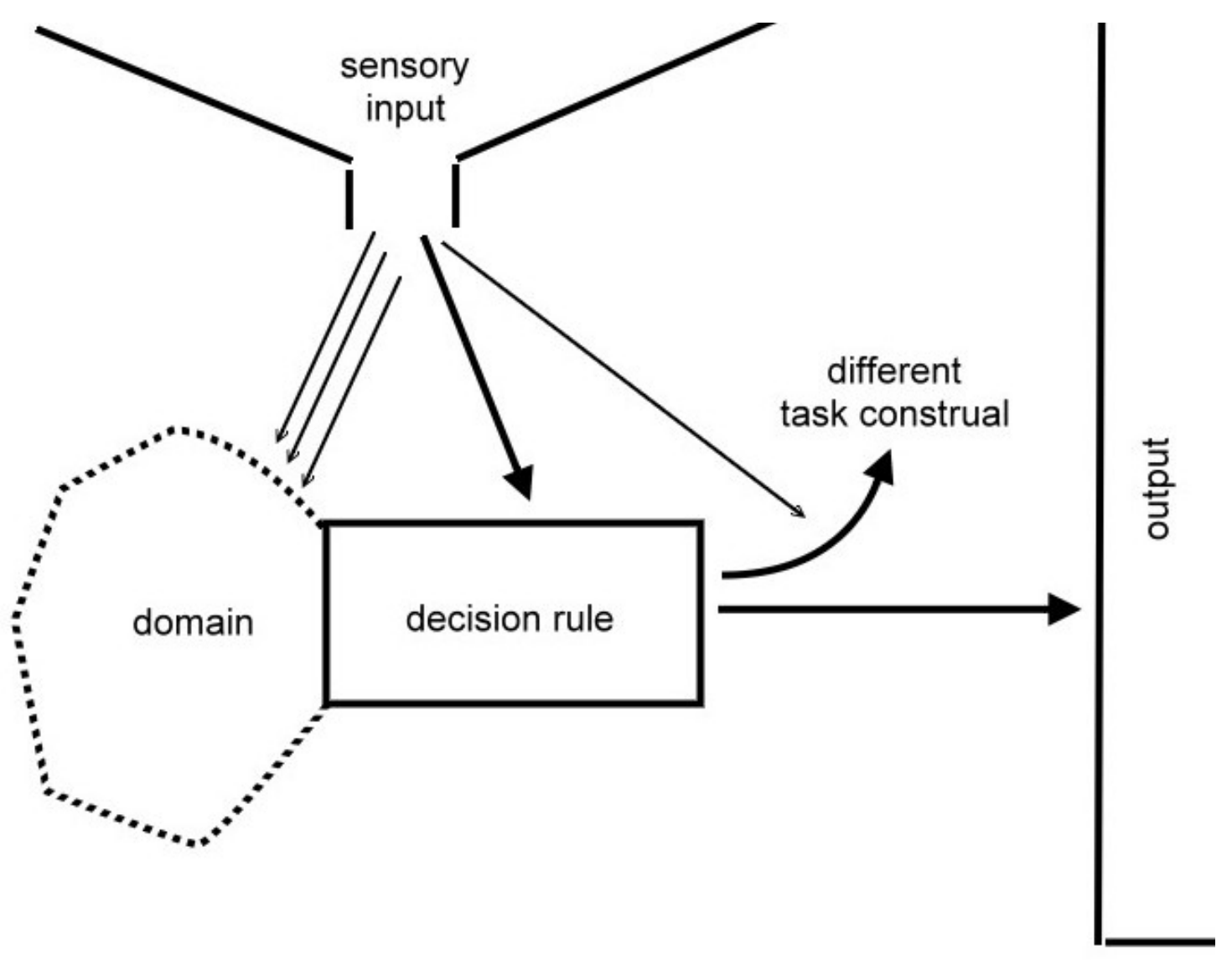

Although the situation can be matched with the domain of the heuristic, and although the individual observes the cue, he nonetheless does not rely on the heuristic.

In the figure, there is deliberately an additional arrow, pointing from sensory input to the additional component of the heuristic. For individuals rarely possess goals they want to see fulfilled regardless of the context. Typically, problems are not out there. Individuals construe tasks in response to information from the environment. If this is the case, adding a separate component for task construal violates the goal of parsimonious modelling. For one may just as well model the 
difference by postulating two or more heuristics with more specialised domains. The separate component is only necessary if one expects problem definition to be generated solely within the brain. Seemingly, the second example fits here. Under the influence of alcohol, the individual's mood changes. But one may just as well model the intervention of mood as impacting on matching, or on the initial retrieval of a heuristic from memory.

\section{Social Dilemmas in a Heuristics Perspective}

Models of behaviour can help students of social dilemmas in two ways. They can allow them to explain perceived social dilemmas. And they can help them predict dilemma situations. Differences in modelling behaviour matter in two cases: a model that takes heuristics into account predicts the absence of a social dilemma where rational choice analysis predicts the presence of one. Conversely, rational choice sees no dilemma in cases in which a dilemma is predicted under the assumption that people can rely on heuristics.

In an epistemologically informed perspective, the difference between explanation and prediction is not categorical. Due to the overwhelming complexity of reality, explanation must rely on the same theoretical constructs that can also be used for prediction. But the field of observation is different. Explanation is backward-looking, prediction is forward-looking. By way of constructing counterfactuals, backward-looking analysis can even chose to explain the absence of a social problem. Such studies are, however, not very frequent. Typically, understanding why a problem predicted by one model is absent in the world of another model is therefore more important for forwardlooking policy advice.

\section{Predicting the Absence of a Social Dilemma}

Rational choice analysis reconstructs behaviour as a reaction to perceived or anticipated changes in the opportunity structure. A whole industry makes a living by showing when the predictions generated by this model are systematically false (OSTROM 1990; FEHR 2000; KAHNEMAN 2000; Ostrom, DiETz et al. 2002). In quite a number of respects, a behaviourally informed model is more optimistic than rational choice analysis. This also holds for the model offered here, i.e. for the model that takes decision-making by heuristics into account.

In a first class of situations, the outcome of using one specific heuristic is more socially beneficial than the outcome achievable with rational reasoning. When this is the case, using this heuristic in decision-making is, socially speaking, a good thing. The "social performance" of the heuristic is better than that of rational reasoning. One proviso is, however, in place. For society, outcome matters, not output. Doing the right thing in the wrong situation is as socially detrimental as doing 
the wrong thing in the first place. Consequently, a heuristic can only be said to be socially beneficial in the abstract if the social benefit is independent of context. This is not very frequent ${ }^{2}$.

The broadspread willingness of most people to keep their promises demonstrates one example of this, however (SCHLICHT 1998: 2, 107 and passim). It removes what rational choice theorists call the second-order prisoners' dilemma: if the original social problem can be reconstructed as a social dilemma, agreeing on a joint solution is irrelevant. For rational actors have no incentive to implement the agreement (OsTROM 1998).

Even more important are features of heuristics that reduce problem pressure from social dilemmas, even if the analyst cannot predict the precise confines of the heuristic actually employed. Note, however, that one could not possibly claim that decision-making by heuristics outperforms rational reasoning, regardless of the contents of the heuristic. For the performance of heuristics categorically rests on their contextuality. This implies that one can never preclude, in the abstract, that individuals will apply heuristics out of area, with socially detrimental effects.

One advantage seems straightforward. Heuristics are simple. Hence using heuristics to make decisions saves mental effort (GIGERENZER, TODD et al. 1999: 327, 351). Scarce mental resources are freed up for more socially beneficial uses. At closer sight, however, only the decision rule is simple. Even if this were a purely probabilistic process, matching information from the environment to the domain of a heuristic would be a demanding endeavour. This holds even more if sense making is implied. But if couched differently, the scarcity argument is warranted. While the mental resources for rational reasoning are fairly limited, the mind is an extremely powerful tool for the parallel processing of sensory input at the subconscious level (SINGER 1991: 103; GLIMCHER 2003). Using heuristics to make decisions transfers most of the mental activity to mental mechanisms that exhibit considerably less scarcity than rational reasoning.

Moreover, due to the make-up of the domain, heuristics are able to exploit much more information from the context than ordinary people can manipulate in conscious reasoning. This explains why switching to rational reasoning makes subjects work harder, but often not smarter (PAYNE, BETTMAN et al. 1997: 200).

When making decisions with heuristics, motivation is only indirectly present: in the description of the domain, and in feedback. Arguably, even the benchmark is relative, not absolute, and it is generated by observing one's peers. Ultimately, important changes in the opportunity structure will nonetheless have an impact on behaviour. But the hyper-reactivity crucial for most of the rational choice predictions is absent. If they use heuristics when deciding, people are likely to ignore small changes completely. There is no anticipation of strategic interaction. People only react if, due to actual strategic interaction, they have suffered significantly. Consequently, it is less likely that an original set of socially beneficial heuristics will be eradicated because of competition. As long as detrimental experiences remain marginal, it is likely that the population will predominantly stick to the original heuristic. Vice versa, socially detrimental behaviour does not instantaneously 
spread throughout the population. It does not affect the behaviour of single individuals as long as nobody engages in it whom they consider to be their peer.

Matching the domain of a heuristic is a demanding cognitive activity. Individuals have to exploit subtle nuances, and engage in sense making. But there is no logical calculation going on. The predictions of rational choice theory for social dilemmas are based on this activity. If people use heuristics, they do not anticipate others' behaviour. They are even less apt to solve complex problems by backwards induction. They do not calculate the expected value of entire strategies, i.e. of chains of action (more from FUDENBERG and TIROLE 1991). Consequently, they are much more likely to choose what is locally appropriate, even if careful calculation would have demonstrated that it is individually less than optimal in the long run.

In rational choice analysis, conflict is pervasive. This is a direct result of methodological individualism. Rational choice is a theory about actors striving for their individually best outcome, no matter what that means for the well-being of their interaction partners. There are heuristics for situations of perceived conflict. Some of them are highly socially detrimental, like those driving vendetta. But if people rely on heuristics, conflict is a matter of domain, not of principle. If individuals do not see a context as conflictual, conflict heuristics will not apply, even if the situation can be reconstructed as a conflict in rational choice terms.

Conflictuality is only one possible feature of the domain. If the perception of social dilemmas is not erroneous, there must be more heuristics that can have socially detrimental effects. But due to the fundamental contextuality of heuristics, this effect is likely to be confined to the domain of origin (cf. GoLDSTEIN and WEBER 1997: 580). Social problems are compartmentalised. They do not automatically spread across domains.

\section{Explaining Perceived Social Dilemmas}

If one takes heuristics into account, some predictions from rational choice theory become dubious. If so, the need for political intervention vanishes. But social dilemmas do not disappear altogether. There must therefore be a way of explaining the remaining social dilemmas from a heuristics perspective. One cannot even preclude that new social dilemmas, not visible from a rational choice perspective, will be uncovered.

\section{a. Socially Detrimental Heuristics}

Socially beneficial heuristics can eradicate social dilemmas that are predicted by rational choice. This idea can be turned upside down. Social dilemmas can result from the fact that people rely on socially detrimental heuristics. Illustrations from the area of climate change are not difficult to find. People, for instance, routinely drive to work, instead of using public transportation. Even the basic ideas underlying the rational choice analysis of social dilemmas could be mirrored in socially detrimental heuristics. If nobody can be excluded from a common good, the social detriment 
can be caused by the heuristic: “This is no one's property, you can take it”. And the fact that there is no rivalry in consumption could translate to the heuristics level the following way. The socially beneficial heuristic might be mute: "Do not take something away if its owner wants to use it". Note, however, that the same proviso holds as for socially beneficial heuristics. Socially, outcome matters, not output. Typically, social detriment will therefore result from the interaction between a heuristic and context, not from the heuristic alone, irrespective of context.

\section{b. Architecture of Heuristics}

Again, socially detrimental effects are even more important if they result from the very architecture of heuristics. At first sight, regulatory attention should focus on the decision rule. For here is the action. The cue and the behavioural output are linked in a socially detrimental way. But, as demonstrated earlier, heuristics are context-specific. There is hardly any combination of a cue and an output that is detrimental in every context. Typically, the description of the domain is therefore more socially relevant.

An overly rigid description of the domain is one primary source of social dilemmas (cf. SCHLICHT 1998: 70). A typical scenario is the following: initially, applying a given decision rule to the situation characterised by the domain was as beneficial individually as it was socially. Later, however, the situation changed in socially important ways. In such situations, if the description of the domain is not sufficiently flexible, behaviour becomes sticky. Evolutionary theorists call this overfitting (WEIGEND 1994). This seems likely to pose a major problem for climate change. Over the last decades, the populations of industrialised countries have learned that emissions can be toxic, or otherwise cause locally visible environmental damage. But they have not been taught that $\mathrm{CO}_{2}$ is a problematic substance. Consequently, they have had no reason to acquire heuristics that help minimise the emissions of $\mathrm{CO}_{2}$ gases.

A related effect is compartmentalisation. Here, a socially beneficial heuristic is confined to too narrow of a domain. For instance, people have learned that they should, in the interest of clean air, drive cars with catalysers. Used cars without a catalyser are hard to sell. This is not, however, to say that people have also learned to drive less in the interest of cutting $\mathrm{CO}_{2}$ emissions.

A third effect is more abstract. In some domains, change is too fast for heuristics to adapt quickly enough. In such contexts, regulation can be interpreted as a way of dividing labour. Adopting or generating a new set of heuristics is aided by measures that make the need for change salient. In appropriate cases, the regulator might even offer alternative, socially more beneficial heuristics. This too can be demonstrated in reference to climate change. If scientists are right, waiting until the effects of climate change are patent would be disastrous. Once the process has gained momentum, it becomes extremely difficult, if not impossible, to stop it. In such situations, without intervention, socially less harmful heuristics will only be adopted by coincidence.

In a second set of cases, the social dilemma results from poor matching (cf. ANDERSON, BoTHELL et al. 2003: ***19). The individual heuristic is applied outside of the area it was adopted for. This 
is not unlikely, given the make-up of the domain. The brain does not expect full matching between the schema or the exemplar and sensory input from the environment. Consequently, a heuristic can sometimes be applied, although the case at hand exhibits important features that do not match the normal context in which it is used. This is particularly likely if the case in most respects resembles a standard situation from the environment of the actor, but differs in one important dimension.

\section{c. Initial Choice of Heuristics}

In many situations, there is initially more than one heuristic that the individual might apply. In such situations, choosing a socially inadequate heuristic can be detrimental. This can result from the fact that a socially less beneficial heuristic outperforms the socially more attractive one in initial choice.

Initial choice is heavily reliant upon memory. Consequently, social problems can result from the properties of retrieval. The recency effect explains priming. We are much more likely to use a heuristic in a new context if we have recently employed it in other contexts (ANDERSON 2000: 206-209). The associational component of retrieval explains the power of mental models. If individuals reconstruct reality in a socially harmful manner, they are likely to rely on socially detrimental heuristics. This explains how ideology can interact with heuristics. But the normative component can be much weaker. In the case of climate change, the social problem can largely be explained by the fact that most individuals reconstruct environmental problems as qualitative, not as quantitative problems. Consequently, they are prepared to switch from one technology or from one substance to another. But they are not likely to extend heuristics for economizing into the areas that are relevant for cutting $\mathrm{CO}_{2}$ emissions.

Since socially beneficial heuristics must be retrieved from memory, a social dilemma can also result from forgetting. In such cases, although the individuals once learned the right heuristic, it is highly unlikely that they will retrieve it when this would be socially beneficial. At the abstract level, forgetting can result from one of three effects: decay, interference, and lost access to the cue necessary for retrieval (ANDERSON 2000: 226).

By contrast, from a heuristics perspective, social dilemmas can be latent. Within the memory of a sufficiently large part of the population, there is a socially detrimental heuristic. It is currently rarely used. But as a result of a change in the environment, many people retrieve this old heuristic. A mere shift in how a situation is presented to the population may also result in retrieving a previously used heuristic. The presence of such socially detrimental heuristics in memory is particularly likely in periods after fundamental changes. For instance, if a population has recently been freed from dictatorship, for quite some time old behavioural programmes will still be mentally available. Likewise, immigrants do come with mental histories. Some of them may bring heuristics that cause harm in their new environment. 


\section{d. Search for Facts}

In principle, social dilemmas can also result from too many searches for facts. Regulatory addressees who actively search for ways to circumvent the new rule demonstrate how this can happen (WEGNER 1996). But in accord with a heuristics perspective, the opposite situation can cause a problem, too. People are too attentive to vivid evidence, and not attentive enough to pallid evidence. They do not engage in any active searches for facts, or they stop their searches too early. Again, this can be illustrated in reference to the climate change issue. As long as the message has not spread that $\mathrm{CO}_{2}$ emissions are a social problem, people are unlikely to switch to heuristics that are socially less problematic. They might, for instance, replace fossil fuels with other forms of primary energy. Or different heuristics might allow them to generate the same final utility with less energy input. Detrimental heuristics might even result in deliberately ignoring information that would lead to socially less harmful activity (cf. BARON and KERR 2003: 163). A classic illustration is behaviour misled by stereotypes (BARGH, CHEN et al. 1996).

\section{e. Acquisition of New Heuristics}

Yet, a social dilemma cannot just result from neglecting to search for facts. One can also result if the spread of socially more beneficial heuristics is inhibited. There are cases in which forerunners long ago adopted a type of behaviour that would lead to the disappearance of some social dilemma. But the large majority is simply unaware of this behavioural alternative. Note that the effect can be purely cognitive. If the majority knew about the alternative, it is arguable that they would be willing to switch to it. Or perhaps individuals are just indifferent about both alternatives. But they could be convinced that it is necessary to fix the social problem.

The opposite situation also exists. A social dilemma sometimes results from the fact that too many are lured into bad habits. For instance, when buying a car, they choose fashionable "sport utility vehicles”, although their energy consumption is much higher.

Happily, for most social dilemmas, only aggregate effects matter. When this is the case, the individual generation of a socially detrimental heuristic due to blending is of little concern, socially speaking. Regulators only need to see to it that the bad heuristic does not spread throughout society. This explains why, in accord with a heuristics perspective, biased feedback is often not a strong concern.

\section{f. Switch to Rational Reasoning}

Behaviour guided by heuristics is not necessarily more beneficial than behaviour resulting from rational reasoning. It can even be more detrimental. This is the case, for instance, if a socially detrimental heuristic is not rational from the indivudualist perspective either. But there is also the opposite possibility: as long as a sufficiently large portion of the population relies on heuristics, the social dilemma is absent, or it is at least less harmful. Actually, this is the case whenever rational choice analysis would predict a social dilemma that is not present from a heuristics perspec- 
tive. In this case, the social dilemma can also be said to result from the fact that too many individuals have switched to rational reasoning.

\section{g. Prospects}

As should be apparent, this paper is an exercise in partial analysis. It invites the following complements: in a heuristics perspective, context matters. Consequently, social dilemmas are not only caused by behaviour. They can also result from socially unfavourable contexts. One element of the status quo ante is particularly relevant for policy-makers. In a heuristics perspective, the analysis cannot start from a hypothetical, institution-free state of nature. Today's social dilemmas can result from yesterday's institutional interventions. Practically speaking, it can be much harder to cure the true institutional cause of a problem. It can be more promising to use a further institutional act of intervention to target heuristics that were shaped by earlier institutions.

Using heuristics to make decisions increases behavioural variance. Many effects other than utilitymaximisation must be taken into account. Both perceived situation and personality matter (MisCHEL and PEAKE 1982; SHODA 1999). For an uninformed interaction partner, this could create an almost insurmountable problem of predictability if he tried to rationally anticipate all potential effects (ENGEL 2004). The same would hold for government if it wanted to rationally design its forms of intervention. But of course, in reality neither government nor interaction partners assume behaviour to be random. Only rational choice analysts do. Precisely because behaviour is contextual, it often is possible to venture a good guess - but no more than that.

Finally, and most importantly, this analysis is confined to problem definition. In a further step, it would have to translate these results into behaviourally informed institutional design. How can purposeful design exploit the generic knowledge about decision-making using heuristics? Would such an approach be acceptable from the perspective of the rule of law and the principle of democracy? These questions need to be addressed. But they are the topic for another paper. 


\section{References}

Anderson, John R. (2000). Learning and Memory. An Integrated Approach. New York, Wiley.

Anderson, John R., Daniel Bothell, et al. (2003). "An Integrated Theory of the Mind." Psychological Review: ***.

Anderson, John R. and Christian Lebiere (2003). "The Newell Test for a Theory of Mind." Behavioral and Brain Sciences: ***.

Bandura, Albert (1986). Social Foundations of Thought and Action. A Social Cognitive Theory. Englewood Cliffs, N.J., Prentice-Hall.

BArgh, John A., Mark Chen, et al. (1996). "Automaticity of Social Behavior. Direct Effects of Trait Construct and Stereotype Activation on Action." Journal of Personality and Social Psychology 71: 230-244.

Baron, Robert S. and Norbert L. Kerr (2003). Group Process, Group Decisions, Group Action. Philadelphia, PA, Open University Press.

BARTLETt, FrederiC C. (1932). Remembering. A Study in Experimental and Social Psychology. Cambridge, [Eng.], The University Press.

Becker, Gary Stanley (1976). The Economic Approach to Human Behavior. Chicago, University of Chicago Press.

Berger, Peter L. and Thomas Luckmann (1967). The Social Construction of Reality. A Treatise in the Sociology of Knowledge. Garden City, N.Y., Doubleday.

Blaug, MARK (1980). The Methodology of Economics. Or, How Economists Explain. Cambridge [Eng.] ; New York, Cambridge University Press.

Bru, Lluís and Xavier Vives (2002). "Informational Externalities, Herding, and Incentives." Journal of Institutional and Theoretical Economics 158: 91-105.

Chomsky, NoAm (1959). "A Review of B.F. Skinner's Verbal Behavior." Language 35: 26-58.

Coleman, James Samuel (1990). Foundations of Social Theory. Cambridge, Mass., Belknap Press of Harvard University Press.

Cornes, Richard and Todd SAndler (1996). The Theory of Externalities, Public Goods and Club Goods. Cambridge, Cambridge University Press.

Dawes, Robyn M. (1999). "A Message from Psychologists to Economists: Mere Predictability Doesn't Matter Like it Should (Without a Good Story Appended to It)." Journal of Economic Behavior and Organization 39: 29-40. 
ENGEL, CHRISTOPH (2004). Generating Predictability. A Neglected Topic in Institutional Analysis and Institutional Design.

Engel, Christoph, Jost Halfmann, et al., Eds. (2002). Wissen, Nichtwissen, Unsicheres Wissen. Common Goods: Law, Politics and Economics 8. Baden-Baden, Nomos.

ENGISCH, KARL (1983). Einführung in das juristische Denken. Stuttgart, Kohlhammer.

FEHR, ERnst (2000). "Cooperation and Punishment in Public Goods Experiments." American Economic Review 90: 980-994.

Friedman, Milton (1953). Essays in Positive Economics. Chicago, University of Chicago Press.

Fudenberg, Drew and Jean Tirole (1991). Game Theory. Cambridge, Mass., MIT Press.

Gigerenzer, Gerd, Peter M. Todd, et al. (1999). Simple Heuristics that Make us Smart. New York, Oxford University Press.

Glimcher, Paul W. (2003). Decisions, Uncertainty, and the Brain. The Science of Neuroeconomics. Cambridge, Mass., MIT Press.

Goldstein, William M. and Robin M. Hogarth (1997). Judgment and Decision Research. Some Historical Context. Research on Judgement and Decision Making. William M. Goldstein und Robin M. Hogarth. Cambridge, Cambridge University Press: 3-65.

Goldstein, William M. and Elke U. Weber (1997). Content and Discontent. Indications and Implications of Domain Specificity in Preferential Decision Making. Research in Judgement and Decision Making. William M. Goldstein und Robin M. Hogarth. Cambridge, Cambridge University Press: 566-617.

Granovetter, Marc (1985). "Economic Action and Social Structure. The Problem of Embeddedness." American Journal of Sociology 91: 481-510.

HeAd, HenRy (1920). Studies in Neurology. Oxford, Oxford University Press.

HebB, Donald O. (1949). The Organization of Behavior. A Neuropsychological Theory. New York, Wiley.

Hodgson, Geoffrey Martin (1988). Economics and Institutions. A Manifesto for a Modern Institutional Economics. Philadelphia, University of Pennsylvania Press.

Hogarth, Robin M., Brian J. GiBbS, et al. (1997). Learning from Feedback. Exactingness and Incentives. Research on Judgement and Decision Making. William M. Goldstein und Robin M. Hogarth. Cambridge, Cambridge University Press: 244-284. 
Kahneman, Daniel (2000). Experienced Utility and Objective Happiness. A Moment-Based Approach. Choices, Values, and Frames. Daniel Kahneman und Amos Tversky. Cambridge, Cambrdige University Press: 673-692.

LASHLey, Karl S. (1951). The Problem of Serial Order in Behaviour. Cerebral Mechanisms in Behaviour. Lloyd A. Jeffress. New York, Wiley: 112-146.

Levinson, StePhen C. (1995). Interactional Biases in Human Thinking. Social Intelligence and Interaction. Esther Goody. Cambridge, Cambridge University Press: 221-260.

LEWIS, Marc D. (2004). "Bridging Emotion Theory and Neurobiology Through Dynamic Systems." Behavioral and Brain Sciences ${ }^{* * *}$ : ***.

MantZavinos, Chrysostomos (2001). Individuals, Institutions, and Markets. Cambridge, UK, Cambridge University Press.

Mischel, Walter and Philip K. Peake (1982). "Beyond déjà vu in the Search for CrossSituational Consistency." Psychological Review 89: 730-755.

National Research Council (2001). Climate Change Science. An Analysis of Some Key Questions. Washington, National Academy of Sciences.

NisBetT, Richard E. and LeE Ross (1980). Human Inference. Strategies and Shortcomings of Social Judgment. Englewood Cliffs, N.J., Prentice-Hall.

Ostrom, ELINOR (1990). Governing the Commons. The Evolution of Institutions for Collective Action. Cambridge; New York, Cambridge University Press.

Ostrom, Elinor (1998). "A Behavioral Approach to the Rational Choice Theory of Collective Action." American Political Science Review 92: 1-22.

Ostrom, Elinor, Thomas Dietz, et al., Eds. (2002). The Drama of the Commons. Washington, National Academy Press.

Payne, John W., James R. Bettman, et al. (1997). The Adaptive Decision Maker. Effort and Accuracy in Choice. Research on Judgement and Decision Making. Currents, Connections, and Controversies. William M. Goldstein und Robin M. Hogarth. Cambridge, Cambridge University Press: 181-204.

Pennington, Nancy and Reid Hastie (1993). "Reasoning in Explanation-Based DecisionMaking." Cognition 49: 123-163.

Pennington, NAncy and Reid Hastie (1997). Explanation-Based Decision Making. Effects of Memory Structure on Judgement. Research in Judgement and Decision Making. William M. Goldstein und Robin M. Hogarth. Cambridge, Cambridge University Press: 454-481. 
Piaget, Jean and Marjorie Gabain (1932). The Moral Judgment of the Child. London, Trubner.

RAKISON, DAVID H. and LISA M. OAKES (2003). Early Category and Concept Development. Making Sense of the Blooming, Buzzing Confusion. Oxford; New York, Oxford University Press.

SaVAge, LeOnard J. (1954). The Foundations of Statistics. New York, Wiley.

SCHLICHT, EKKEHART (1998). On Custom in the Economy. Oxford, Clarendon Press.

Selten, Reinhard (1998). "Aspiration Adaptation Theory." Journal of Mathematical Psychology 42: 191-214.

Shafir, Eldar, ItAmar Simonson, et al. (2000). Reason-Based Choice. Choices, Values, and Frames. Daniel Kahneman und Amos Tversky. Cambridge, Cambridge University Press: 597-619.

SHOdA, Yuichi (1999). "A Unified Framework for the Study of Behavioral Consistency. Briding Person x Situation Interaction and the Consistency Paradox." European Journal of Personality 13: 361-387.

Simon, Herbert Alexander (1955). "A Behavioural Model of Rational Choice." Quarterly Journal of Economics 69: 99-118.

Simon, Herbert Alexander (1972). Theories of Bounded Rationality. Decision and Organisation. A volume in honour of Jacob Marschak. Charles B. McGuire und Roy Radner. Amsterdam, North Holland: Chapter 8.

Simon, Herbert AleXAnder (1979). "Rational Decision Making in Business Organisations." American Economic Review 69: 493-513.

SingER, Wolf (1991). Die Entwicklung kognitiver Strukturen - ein selbstreferentieller Lernprozess. Gedächtnis: Probleme und Perspektiven der interdisziplinären Gedächtnisforschung. Siegfried J. Schmidt. Frankfurt, Suhrkamp: 96-126.

SINGER, Wolf (2003). Hirnentwicklung - neuronale Plastizität - Lernen. Lehrbuch der Physiologie. Rainer Klinke und Stefan Silbernagl. Stuttgart, Thieme: 743-756.

Skinner, B. F. (1938). The Behavior of Organisms. An Experimental Analysis. New York, Appleton-Century.

STRACK, FRITZ and ROLAND DEUTSCH (2002). Reflective and Impulsive Determinants of Social Behaviour. ***

Thompson, M., Richard Ellis, et al. (1990). Cultural Theory. Boulder, Colo., Westview Press. 
TuRner, MARK (2001). Cognitive Dimensions of Social Science. New York, Oxford University Press.

WEGNER, GERHARD (1996). Wirtschaftspolitik zwischen Selbst- und Fremdsteuerung - ein neuer Ansatz. Baden-Baden, Nomos.

Weigend, A (1994). On Overfitting and the Effective Number of Hidden Units. Proceedings of the 1993 Connectionist Models Summer School. Michael C. Mozer. Hillsdale, New Jersey, LEA: 335-342. 